\title{
Efficiency Enhancement of Leakage Current Reduction in Three Phase Transformerless Solar Systems
}

\author{
${ }^{1}$ Mrs. V.Jayalakshmi, Assistant Professor, ${ }^{2}$ Ms. K. Anusuya, P.G. Scholar \\ ${ }^{1,2}$ Department of Electrical and Electronics Engineering, Bharath University, Chennai-73, Tamil Nadu, India
}

\begin{abstract}
This paper presents a modified z-source inverter which is an effective method for reduction of leakage current in three phase transformer less grid connected PV systems. Another modulation technique along with z-source used are space vector pulse width modulation technique which improves the accuracy of leakage current by maintaining common mode voltage (CMV) constant. The new topology only requires an potential isolator which stabilize the leakage current output from the z-source inductanceand a fast recovery diode comparing with original structure. Simulation results for the three-phase transformerless PV system operating in two cases, i.e., connected to a grid and connected to a grounded RL load, are presented. The SVM control algorithm presented in this paper is implemented through Matlab/Simulink tool and verified.
\end{abstract}

Index Terms: Energy conversion, photovoltaic (PV) power systems, pulse width-modulated power converters.

\section{Introduction}

Traditionally power inverters can be broadly classified either as voltage-source inverter (VSI) or current source inverter (CSI). They both suffer from the common limitation that they are either boost or buck converter and cannot be a buck-boost converter. That is, their obtainable output voltagerange is limited to either greater or smaller than the input voltage. Also their main circuits are not interchangeable and they are vulnerable to EMI noise in terms of reliability. Z-source inverters (ZSI) have been recently proposed as an alternative power conversion concept as they can have bothvoltage buck and boost capabilities. Fig.1. shows the main circuit of the Z-source inverter. It employs a unique impedance network coupled between the power source and the converter circuit that consists of a split-inductor L1 and L2 and capacitors $\mathrm{C} 1$ and $\mathrm{C} 2$ connected in $\mathrm{X}$ shape. The X-armscouple the inverter to a DC voltage source. The voltage source may be a battery, a diode rectifier or a fuel cell. This unique impedance network allows the Z-source inverter to buck or boost its output voltage, and also provides it with unique features that cannot be achieved in traditional power inverters. Many pulse-width modulation (PWM) control methods have been developed and used for the traditional three phase voltage source inverter. The traditional VSI has six active vectors when the dc voltage is impressed across the load and two zero vectors when the load terminals are shorted through either the lower or upper three devices. These total eight switching states and their combinations have spawned many PWM control schemes. On the other hand, Z source inverter has additional zero vectors or shoot-through switching states that are forbidden in the traditional VSI, both switches of any phase leg can never be gated on at the same time or a short circuit (shoot through) would occur and destroy the inverter. The new Z-source inverter (ZSI) advantageously utilizes the shoot through state to boost the dc bus voltage by gating on both upper and lower switches of a phase leg and produce a desired output voltage that is greater than the available dc bus voltage. In addition the reliability of the inverter is greatly improved because the shoot-through due to misgating can no longer destroy the circuit. Thus it provides a low-cost, reliable, and high efficiency single stage structure for buck and boost power conversion. In [1], the operation principle and the shoot through duty ratio control using simple boost control method have been described in detail.

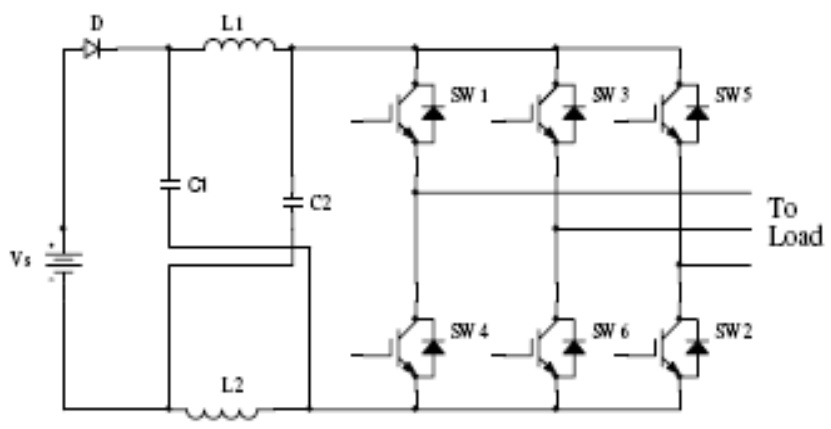

Fig.1. Z-Source inverter 


\section{Carrier Based Pwm Control Methods}

For an output voltage boost to be obtained, a shootthrough state should always be followed by an active state, i.e., shoot through states should be incorporated without affecting the active states. Thus, minor modifications in the traditional three phase sinusoidal PWM technique will yield variousPWM control strategies for the ZSI. There are three available PWM control strategies for ZSI. They are simple boost control, maximum boost control, and maximum constant boost control methods.

The simple boost control method employs two straight envelops equal to or greater than the peak value of the three phase sinusoidal reference signals to control shoot-through duty ratio in a traditional sinusoidal PWM. The circuit is in shoot through state when the high frequency triangular carrier is greater than the upper straight line envelope or lesser than the lower straight line envelope. In this method the voltage stress across the switches is quite high, which restrict the obtainable voltage gain because of the limitation of device voltage rating. As during shoot through all the switches are $\mathrm{ON}$, switching losses are high.

The maximum constant boost control is quite similar to the traditional carrier-based PWM control method, but this control method maintains the six active states unchanged and turns all zero states into shoot through zero states. The circuit is in shoot through state when the triangular carrier wave is greater than the maximum curve of the reference or lesser than the minimum curve of the reference. This method turns all the zero states into shoot through state thus minimizing the voltage stress across the switches. However it causes shootthrough duty ratio to vary in each cycle, thus increasing the ripple content in inductor current. When the output frequency is low, the inductor ripple becomes significant and a large inductor is required. This increases the cost and size of the circuit.

In maximum constant boost control method the straight envelops of simple boost control method are replaced by two sinusoidal signals of three times the frequency of sinusoidal modulating signals. Thus this method involves three referencesinusoidal signals and two shoot through envelopes. The circuit enters shoot through state whenever the high frequency triangular wave is greater than the upper shoot-through envelope or lesser than the lower shoot-through envelope. This method achieves maximum boost while keeping shoot through duty ratio constant all the time, thus reducing ripple content in inductor current.

In order to reduce leakage currents present in transformerless PV systems (grid connected or stand alone with grounded load), it is necessary to maintain the CMV constant in the inverter, i.e., not having switching. Therefore, in this paper, the ZSIwith an additional fast-recovery diode (named ZSI-D), using specific PWM techniques that maintain the CMV constant, isproposed to reduce leakage currents. The maximum amplitude of the output voltages can reach high levels due to the boostcharacteristic of the ZSI, and thus, less PV modules in series areneeded to connect the system to the grid without a transformer.Furthermore, a proper switching pattern is chosen in order toassure a reduced number of commutations, leading to reduced switching losses in the inverter. Thus the leakage current in inductance can be avoided by using the z-source inverter and by maintaining the constant common mode voltage throughout the system.

\section{Proposed Space Vector Pwm Control}

Space vector PWM is amodulation technique for three phase inverters. Total eight switching stats: 6 active states and two zero states. Duty cycles of switch are computed from the selected state vectors out of eight possible switching vectors. The main advantage of SVPWM is the flexibility to choose space vectors and their placement in the switching cycle to achieve required performance specifications for the inverter with minimum switching transitions. Space vector PWM refers to special switching sequence of the upper three switches of the inverter. It has been shown to generate less harmonic distortion in the output voltage and current applied to the phases of an ac motor and to provide more efficient use of supply voltage compared with sine PWM technique. For a voltage source inverter the SVPWM can be implemented with the following algorithm. The modulation index is

$$
a=\frac{\mathrm{V}_{\text {ref }}(1)}{2 / 3 \mathrm{~V}_{\mathrm{S}}}
$$

Switching time durations for active states are

$$
\begin{aligned}
& \mathrm{T} 1=\mathrm{Ts} \cdot \mathrm{a} \cdot \sin \left(\frac{\pi}{3}-\beta\right) / \sin \left(\frac{\pi}{3}\right) \\
& \text { And } \\
& \mathrm{T} 2=\mathrm{Ts} \cdot \mathrm{a} \cdot \sin \left((\beta) / \sin \left(\frac{\pi}{3}\right)\right.
\end{aligned}
$$

Switching time duration for zero state is

$T 0=T s-(T 1+T 2)(4)$ 
The shoot-through states will be distributed evenly into the switching period. These states will not change the active vectors in SVPWM algorithm since the shoot-through states and zero states in conventional SVPWM appears the same to the ac side by shorting the inverter three phase output terminals. In conventional SVPWM applied to VSI, the AC voltage vector is limited. That means the AC voltage vector is not available when the magnitude of required voltage beyond the limit imposed by conventional VSI. However, with the proper shootthrough distribution within zero vectors, i.e., the proposed modified SVPWM for ZSI, any AC voltage beyond $2 \mathrm{Vs} / \pi$ could be implemented. The voltage vector through the modified SVPWM is shown in Fig.3. The PWM switching pattern for three phase Z-source inverter in sector-1 is shown in Fig.4. The shoot-through duty ratio which controls the boosted DC link voltage is:

$\mathrm{D}=4 \mathrm{Tst} / \mathrm{Ts}$

\section{Three-Phase Modified Zsi For Transformer Less Pv Systems}

In this section, a three-phase ZSI-D to reduce leakage currents in transformerless PV systems is proposed and the simplified common-mode circuit is analyzed. Fig. 1 shows the ZSI-D, where an impedance network consisting of two identicalinductors and two identical capacitors is used to couple the PV array to the inverter switches. The difference between the traditional ZSI and the proposed one is the additional fastrecovery diode $(D 2)$, which is used to guarantee the completeisolation of both terminals of the PV array from the inverter switches during the shoot-through states. Isolating the PV array during the shoot-through states, when fluctuations occur in the potential between PV cells and grounded PV frame, practically eliminates the leakage currents. During the non-shoot-through states, a proper PWM technique should be used in order to maintain this PV potential constant.

Without a transformer, there is a galvanic connection between grid and PV cells, and thus, a leakage current could appear. For the transformerless grid-connected system in Fig. 1, a resonant circuit is created if the PV frame is grounded. This resonant circuit includes PV array stray capacitances $(C P V)$, which are concentrated in both $P$ and $N$ terminals, filter inductances $(L f)$ with their internal resistance $(R f)$, and resistances between the ground connection ofthe PV frame and grid $(R g)$. It is possible to express the leakage voltage (voltage between positive $(P)$ or negative $(N)$ dc bus and grounded neutral $(n)-v P n$ or $v N n)$ in terms of the inverter output voltages.

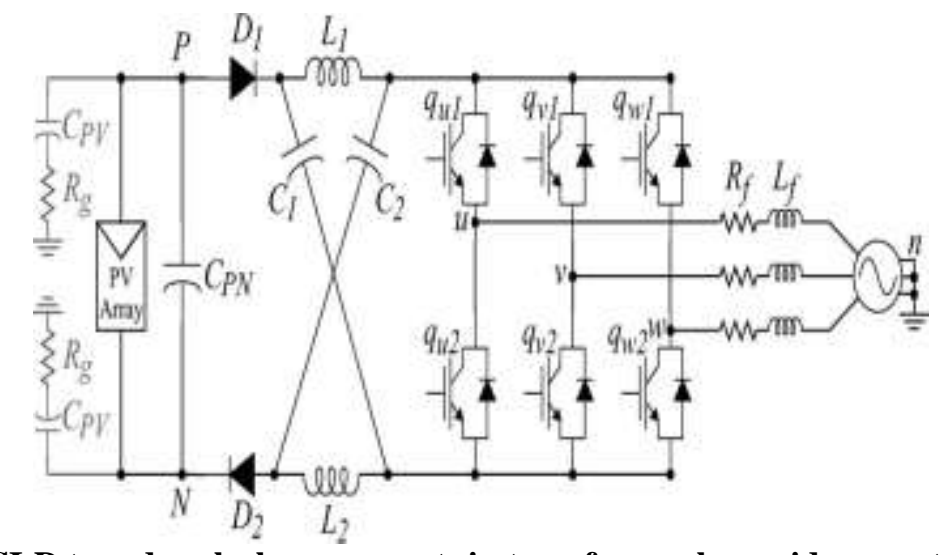

Fig. 2. Three-phase ZSI-D to reduce leakage currents in transformer less grid connected PV systems.

\section{Cmv In Modified Z-Source Inverter}

The space-vector PWM (SVPWM) is generally used to control the three-phase voltage-source inverter (VSI) switches. The eight possible combinations are composed of six active $(V 1, V 2, V 3, V 4, V 5$, and V6) and two zero ( $V 0$ and $V 7$ ) voltage vectors (Fig. 4). In SVPWM, the $\alpha \beta$ plane is divided in six sectors, delimited by the active space vectors. The output reference voltage vector $\left(-\rightarrow v^{*}\right)$ is composed, in average values, by the active vectors that define the sector where it is located and both zero vectors. The maximum amplitude of the output phase-to neutralvoltages $(V *)$ is $v P N / \sqrt{3}$ in the linear region $(m \leq 2 / \sqrt{3}=1.15)$. The modulation index is defined as 


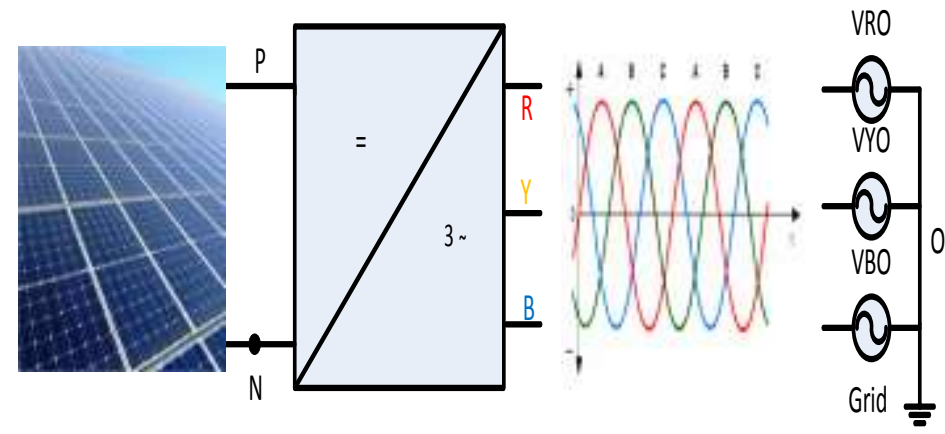

Fig.3.Common mode voltage of 3-ph System

$m=2 V^{*} / \operatorname{Vpn}(6)$

Where $V *$ is the reference (desired) amplitude of the output phase-to-neutral voltages.

The value of leakage current depends on the amplitude and leakage current and frequency content of voltage fluctuations and Cpg. The modulation technique used in the inverter is the most dominant factor in determining common mode voltage and leakage currents.

The common mode voltage for three phase system is defined as:

$v_{C M V}=\frac{v_{R N}+v_{Y N}+v_{B N}}{3}$

Therefore, leakage currents can be attenuated through propercontrol of the CMV. The diode $D 2$ in the proposed ZSI-D allows the opening of the way of leakagecurrents during shoot-through states. Therefore, switching inthe CMV, during shoot-through states, have no effect on leakagecurrents.

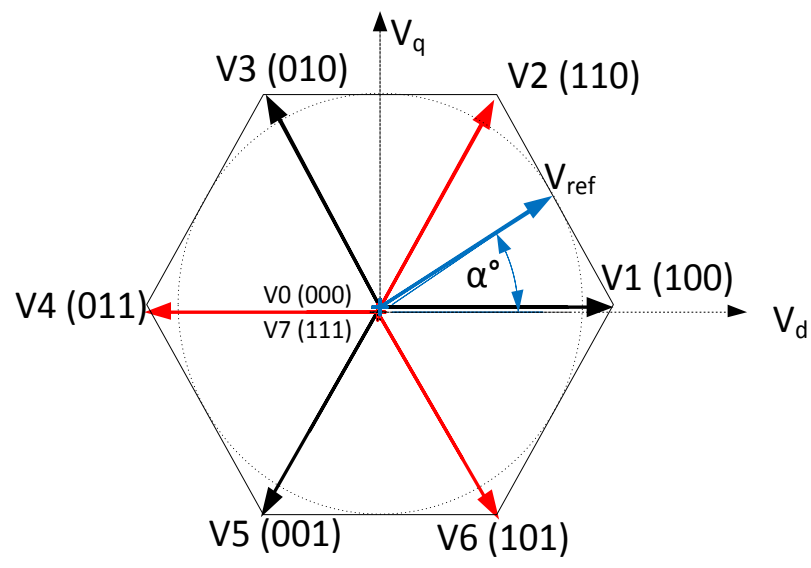

Fig. 4. Output voltage space vectors of a three-phase inverter.

In addition to the eight traditional switching states of a VSI, the ZSI has seven shoot-through zero states (Vust , $V v s t, V w s t$, $u v s t$, $u w s t$, $v w s t$, and $V u v w s t$ ), during which both the upper and lower switches of one or multiple phase legs are turned on totalizing 15 possible combinations. Table I presents the space vectors associated to the possibilities of the ZSI switches 
TABLE I

CORRESPONDING SPACE VECTORS FOR ALL COMBINATIONSOF THE ZSI SWITCHES

\begin{tabular}{c|c|c|c|c|c|c}
\hline$q_{u 1}$ & $q_{v 1}$ & $q_{w 1}$ & $q_{u 2}$ & $q_{v 2}$ & $q_{w 2}$ & Space Vector \\
\hline 0 & 0 & 0 & 1 & 1 & 1 & $V_{0}$ \\
\hline 1 & 0 & 0 & 0 & 1 & 1 & $V_{1}$ \\
\hline 1 & 1 & 0 & 0 & 0 & 1 & $V_{2}$ \\
\hline 0 & 1 & 0 & 1 & 0 & 1 & $V_{3}$ \\
\hline 0 & 1 & 1 & 1 & 0 & 0 & $V_{4}$ \\
\hline 0 & 0 & 1 & 1 & 1 & 0 & $V_{5}$ \\
\hline 1 & 0 & 1 & 0 & 1 & 0 & $V_{6}$ \\
\hline 1 & 1 & 1 & 0 & 0 & 0 & $V_{7}$ \\
\hline 1 & $q_{v 1}$ & $q_{w 1}$ & 1 & $\bar{q}_{v 1}$ & $\bar{q}_{w 1}$ & $V_{s t}^{u}$ \\
\hline$q_{u 1}$ & 1 & $q_{w 1}$ & $\bar{q}_{u 1}$ & 1 & $\bar{q}_{w 1}$ & $V_{s t}^{v}$ \\
\hline$q_{u 1}$ & $q_{v 1}$ & 1 & $\bar{q}_{u 1}$ & $\bar{q}_{v 1}$ & 1 & $V_{s t}^{w}$ \\
\hline 1 & 1 & $q_{w 1}$ & 1 & 1 & $\bar{q}_{w 1}$ & $V_{s t}^{u v}$ \\
\hline 1 & $q_{v 1}$ & 1 & 1 & $\bar{q}_{v 1}$ & 1 & $V_{s t}^{u w}$ \\
\hline$q_{u 1}$ & 1 & 1 & $\bar{q}_{u 1}$ & 1 & 1 & $V_{s t}^{v w}$ \\
\hline 1 & 1 & 1 & 1 & 1 & 1 & $V_{s t}^{u v w}$ \\
\hline
\end{tabular}

\section{Modulation Techniques For The Proposed Zsid}

\section{Proposed modulation technique for reduction of leakage current}

The objective of the proposed PWM techniques is to reduce the high-frequency components of the $\mathrm{CMV}$, in order to reduce leakage currents in the ZSI-D topology. One possible technique [called odd PWM (OPWM)] consists in using only odd active and one-leg shoot-through space vectors to compose the output reference voltages and to boost the PV voltage. Therefore, only the active vectors $V 1, V 3$, and $V 5$ and the shootthrough vectors $V u$ st, $V v$ st, and $V w$ st are used. As can be seen in Table II, this technique guarantees the same CMV during the application ofthe odd active space vectors. During the shoot-through state,there is a change in the CMV, but the leakage currents do nothave a path to circulate in the common-mode circuit due to the reverse-biased diodes $D 1$ and $D 2$ in the proposed ZSID topology.

Therefore, the combination of the ZSI-D topology with the OPWM technique practically eliminates leakage currents in transformer less PV systems. The proposed PWM presents four switching for each active vector change. In order to reduce the number of switching in the active to shoot through transition, the one-leg shoot-through vector is chosen. Furthermore, to assure equal current stress in each inverter output leg during the shoot through state, the one leg shoot-through vector is changed every $120^{\circ}$. One possible combination is as follows: $V$ ust is used from $-60^{\circ}$ to $60^{\circ}, V$ vst isused from $60^{\circ}$ to $180^{\circ}$, and $V$ wst is used from $-180^{\circ}$ to $-60^{\circ}$,completing an output fundamental cycle. It is important to notethat switching in CMV occur only during a transition to orfrom a shoot-through state, when both reversed-biased diodes $D 1$ and $D 2$ block the path for leakage currents. Another possible technique [called even PWM (EPWM)] consists in using only even active space vectors and the one leg shoot-through space vector to compose the output reference voltages and to boost the PV voltage. Therefore, only the active vectors $V 2, V 4$, and $V 6$ and the shoot-through vectors $V u$ st, $V v s t$, and $V$ wst are used. As can be seen in Table II, this technique also guarantees the same CMV during the application of the active space vectors and the same behavior during the shoot-through state.

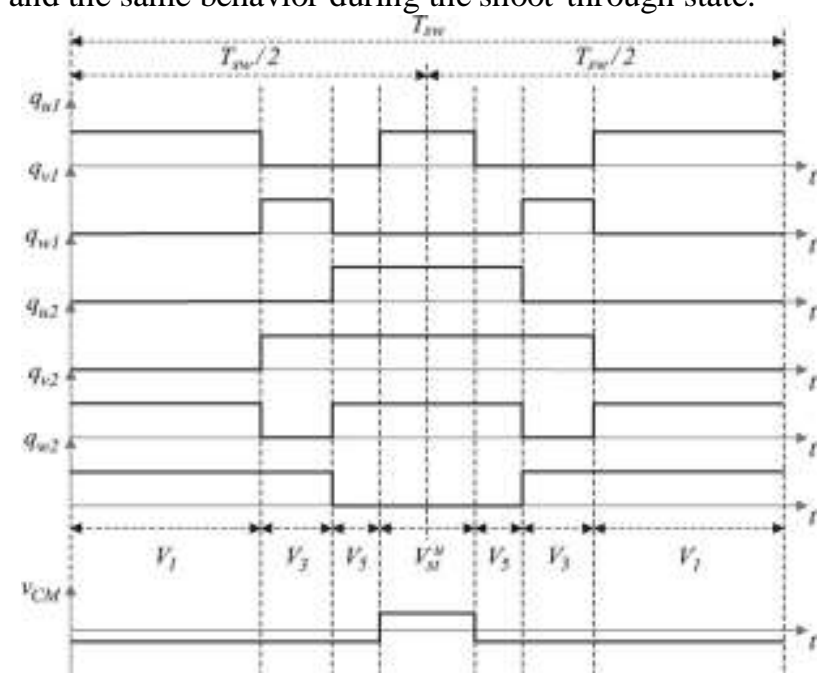

Fig. 5. Switching pattern and CMV in the ZSI-D controlled by OPWM . 
Therefore, the combination of the ZSI-D topology with the EPWM technique also practically eliminates leakage currents in transformerless PV systems. A third possibility [called odd-even PWM (OEPWM)] consists in using a combination of OPWM and EPWM, depending of the position of the output reference voltage vector. In this technique, the tips of odd and even limiting triangles delimit the output voltage synthesis area in a form of a six-point star, as can be seen in Fig.6.

With this technique, subtle changes in CMV occurs every $60^{\circ}$ of the output fundamental cycle, due to changes in the group of the active vectors. Those changes are responsible for six spikes in the leakage currents per fundamental cycle.

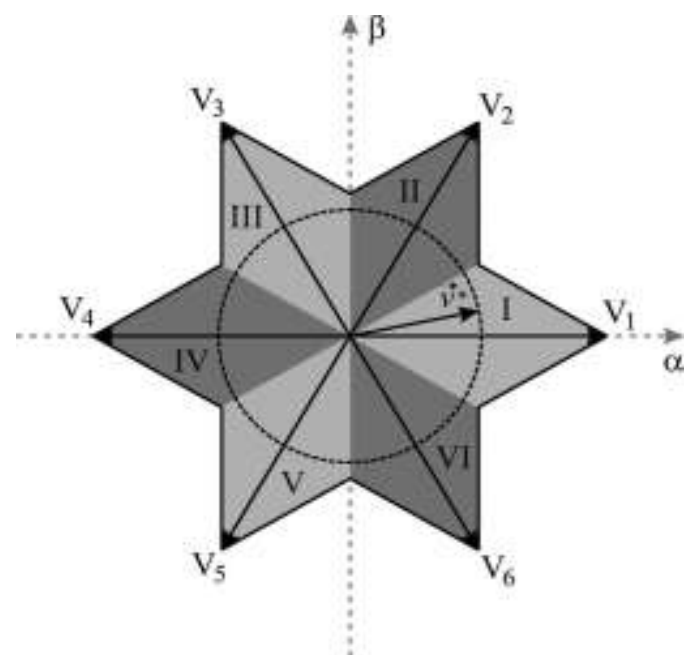

Fig. 6. Output voltage space vectors for OEPWM in the three-phase ZSI-D.

Nevertheless, the rms value of the leakage currents remains low when compared with the leakage current in ZSI with MCB, in which the CMV changes eight times per switching period, corresponding to approximately 1334 spikes in the leakage currents per fundamental cycle (for $T \mathrm{sw}=100 \mu \mathrm{s}$ and the $60-\mathrm{Hz}$ grid).

\section{Simulated Results For Zsi-D}

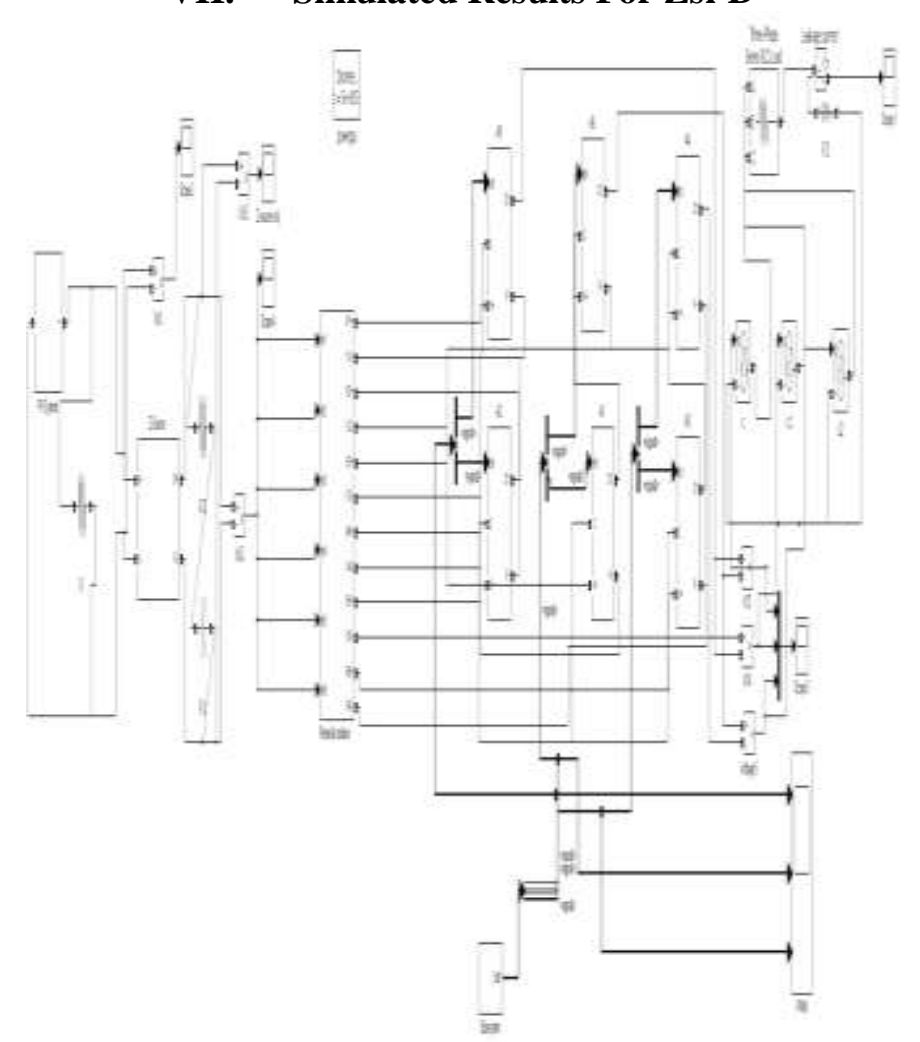

Fig. 7. Simulation model for three phase 5-level z-source inverter 


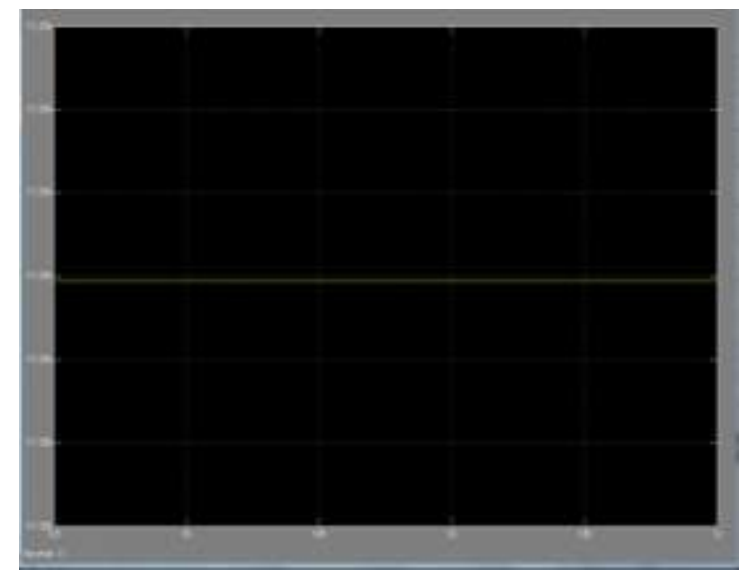

Fig. 8.a. Output DC voltage from photovoltaic system

Fig.8. Shows the simulation model for three-phase z-source inverter in which the PWM is tried till level five in order to improve the accuracy of the leakage current. Potential transformer is included to receive the $\mathrm{z}$-source output, that has unstable dc output voltage. This unstable dc output is made stable by the use of potential transformer. Thus, this dc output is converted into ac using IGBT switches which is triggered for various firing angles with the help of space PWM (SVPM). By triggering the PWM for various levels (e.g. till level five) the steady output leakage current can be obtained which has reduction in high frequency components of the CMV that reduces the leakage current in the three phase transformerless z-source inverter.

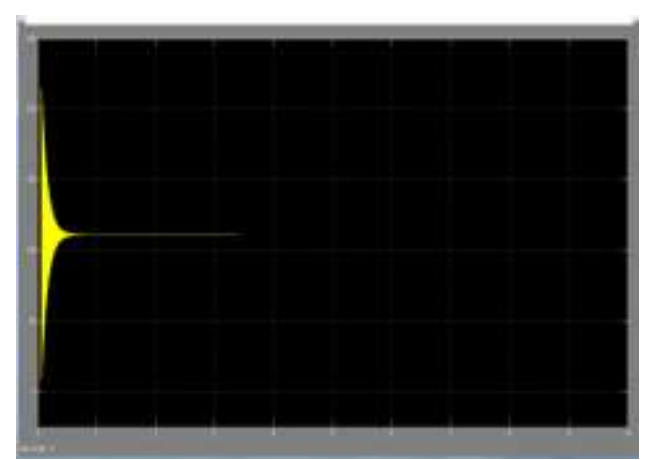

Fig. 8.b. Output DC voltage from z-source inverter

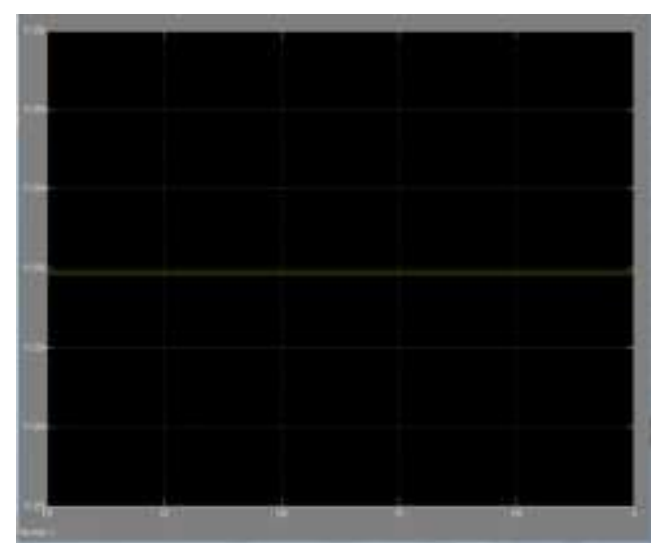

Fig. 8.c. output voltage from potential isolator 


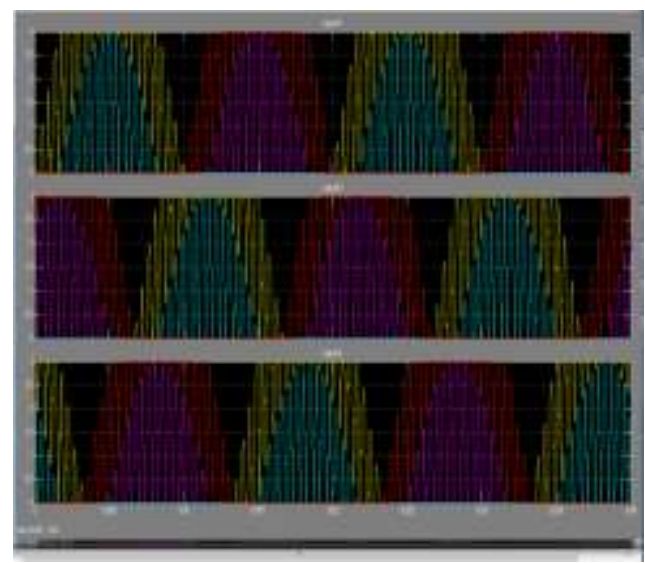

Fig. 8.d. PWM AC output voltage

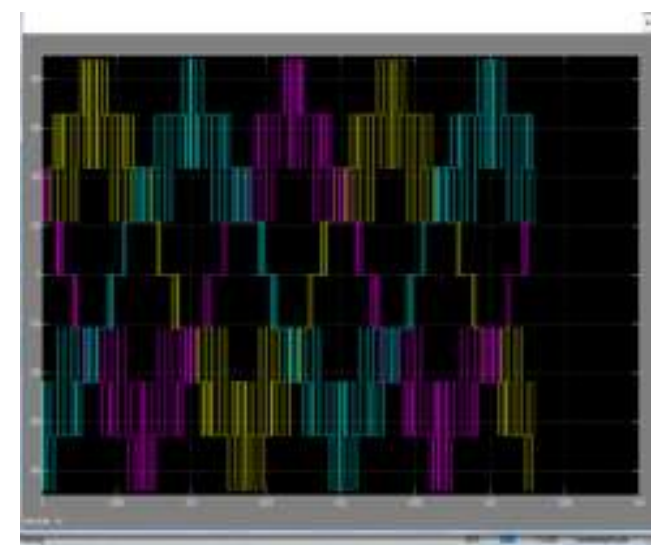

Fig. 8.e.Five Level common mode voltage

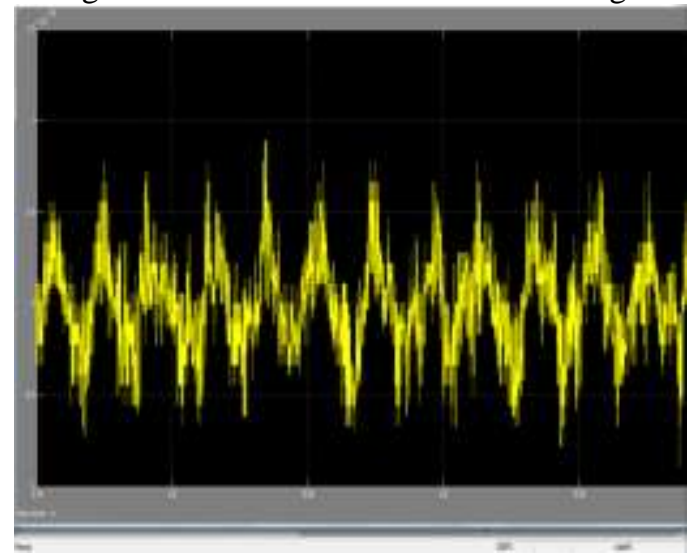

Fig. 8.f. Output leakage current(A)

Fig. 8. Simulation of grid-connected PV transformerless ZSI-D modulated by OPWM 

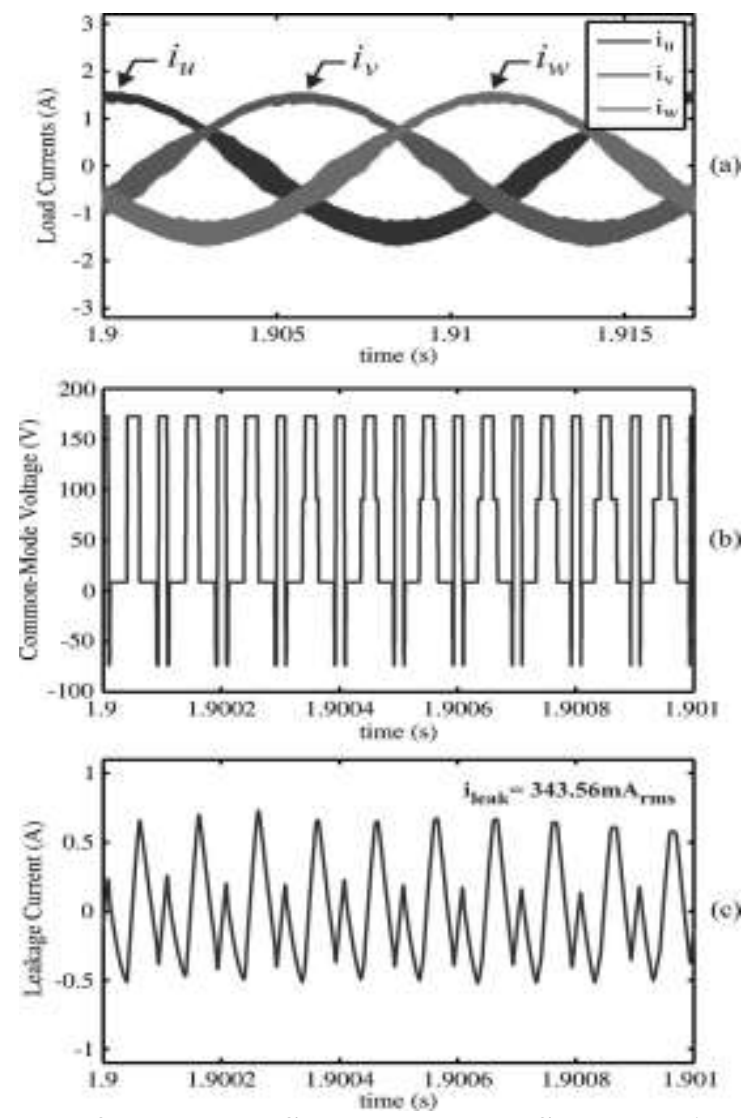

Fig. 9. Simulation of the PV transformerless ZSI modulated by SVPWMwith MCB control connected to a $R L$ load. (a) Load currents. (b) CMV $v$ CM. (c) Leakage current $I_{\text {leak. }}$

Fig. 8 shows the variables of the ZSI-D topology modulated by OPWM. The three-phase grid currents, seen in Fig. 9(f),present lower ripples than the ones in the ZSI, due to low leakage currents flowing through each phase of the grid. Note that the leakage currents in the ZSI-D topology are practically zero, when compared with the leakage currents in the ZSI topology, which reach almost 7.5 A of peak value and4.06 A of rms value. The leakage currents in the ZSI-D topologycan be seen in detail in Fig. 9(f) and reach peak valuesequal to $5 \mathrm{~mA}$ and rms values equal to $3.11 \mathrm{~mA}$. This proves theeffectiveness of the proposed topology and PWM techniques inreducing leakage currents in grid-connected transformerless PVsystems.

The three-phase grid currents, seen in Fig. 8(f), present lower ripples than the ones in the ZSI, due to low leakage currents flowing through each phase of the grid. Note that the leakage currents in the ZSI-D topology are practically zero, when compared with the leakage currents in the ZSI topology, which reach almost 7.5 A of peak value and 4.06 A of rms value. The leakage currents in the ZSI-D topology can be seen in detail in Fig. 8(f) and reach peak values equal to $5 \mathrm{~mA}$ and rms values equal to $3.11 \mathrm{~mA}$. This proves the effectiveness of the proposed topology and PWM techniques in reducing leakage currents in grid-connected transformerless PV systems.Fig.9 shows a simulation result for the ZSI topology modulated by SVPWM with MCB control. The three-phase load currents are shown in Fig. 9(a), and they present high ripples, due to high leakage currents [Fig. 9(c)] flowing through each phase of the load. The CMV $v$ CM, shown in Fig. 9(b), presents four different values Both CMV and leakage current in Fig. 9(b) and (c), respectively, are shown in detail in order to see the CMV's four different levels and their influence in the leakage current.

The Z-source input voltage is fixed in $110 \mathrm{~V}$, and the Z-sourceimpedance has the following values: $L=$ $160 \mathrm{e}^{-6} \mathrm{H}$ and $C=1100 \mu \mathrm{F}$. A shoot-through duty cycle equal to 0.3 is chosen(voltage boost equal to 2.50 and $B B$ $=1.75$ ). The switchingfrequency was fixed in $10 \mathrm{kHz}$, and there is not an output filterbetween inverter and load. The experimental setup is formedby three 1200-V/50-A insulated-gatebipolar transistor (IGBT)modules, one or two 1700-V/60-A fast-recovery diodes, and sixsingle IGBT drivers, all controlled by a floating-point digitalsignal process 


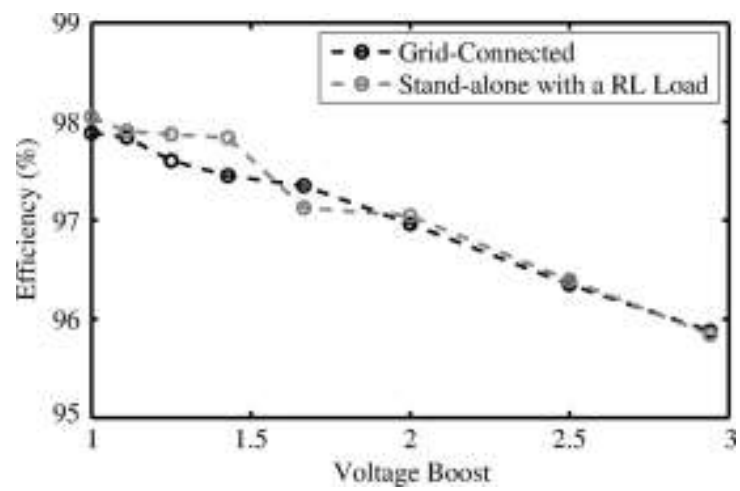

Fig.10. Simulation result of grid-connected and stand-alone ZSI-D efficiency versus voltage boost for a fixed output active power).

\section{Conclusion}

This paper proposes a modified topology of ZSI to be applied in three-phase transformerless PV systems. Three modulation techniques combined with the ZSI topology guarantee constant CMV during the application of active vectors and complete isolation of the PV array during the shoot-through vectors, that improves the behavior of the system in terms of leakage currents with only an additional fast-recovery diode. The traditional and modified three-phase transformerless ZSIs were simulated in two load conditions ( $R L$ load and grid connected), and experimental prototypes of both topologies connected to a $R L$ load were tested to evaluate leakage currents. Simulation results verified the effectiveness of the proposed modulation technique. Moreover it has low switching losses, less ripples, and improved efficiency when comparing with existing technique.

\section{References}

[1] F. Blaabjerg, R. Teodorescu, M. Liserre, and A. V. Timbus, "Overviewof control and grid synchronization for distributed power generationsystems," IEEE Trans. Ind. Electron., vol. 53, no. 5, pp. 1398-1409, Oct. 2006.

[2] M. Liserre, A. Pigazo, A. Dell'Aquila, and V. M. Moreno, "An antiislandingmethod for single-phase inverters based on a grid voltage sensorlesscontrol," IEEE Trans. Ind. Electron., vol. 53, no. 5, pp. 1418-1426, Oct. 2006.

[3] F. Blaabjerg, Z. Chen, and S. B. Kjaer, "Power electronics as efficientinterface in dispersed power generation systems," IEEE Trans. PowerElectron., vol. 19, no. 5, pp. 1184-1194, Sep. 2004.

[4] E. Gubía, P. Sanchis, A. Ursua, J. Lopez, and L. Marroyo, "Ground currentsin single-phase transformerless photovoltaic systems," Prog. Photovolt.:Res. Appl., vol. 15, no. 7, pp. 629-650, Nov. 2007.

[5] T. Kerekes, R. Teodorescu, P. Rodriguez, G. Vazquez, and E. Aldabas, "Anew high-efficiency single-phase transformerless PV inverter topology,"IEEE Trans. Ind. Electron., vol. 58, no. 1, pp. 184-191, Jan. 2011.

[6] S. B. Kjaer, J. K. Pedersen, and F. Blaabjerg, "A review of single-phasegrid-connected inverters for photovoltaic modules," IEEE Trans. Ind.Appl., vol. 41, no. 5, pp. 1292-1306, Sep./Oct. 2005.

[7] M. Garcia, J. M. Maruri, L. Marroyo, E. Lorenzo, and M. Perez, "Partialshadowing, MPPT performance and inverter configurations: Observationsat tracking PV plants,” Prog. Photovolt.: Res. Appl., vol. 16, no. 6,pp. 529-536, Sep. 2008.

[8] P. Sanchis, J. Lopez, A. Ursua, E. Gubia, and L. Marroyo, "On the testing characterization, and evaluation of PV inverters and dynamic MPPTperformance under real varying operating conditions," Prog. Photovolt.:Res. Appl., vol. 15, no. 6, pp. 541-556, Sep. 2007.

[9] F. Z. Peng, “Z-source inverter," IEEE Trans. Ind. Appl., vol. 39, no. 2,pp. 504-510, Mar./Apr. 2003.

[10] Y. Tang, S. Xie, C. Zhang, and Z. Xu, "Improved Z-source inverter withreduced Z-source capacitor voltage stress and soft-start capability,” IEEETrans. Power Electron., vol. 24, no. 2, pp. 409-415, Feb. 2009.

[11] Y. Huang, M. Shen, F. Z. Peng, and J. Wang, "Z-source inverter forresidential photovoltaic systems," IEEE Trans. Power Electron., vol. 21,no. 6, pp. 1776-1782, Nov. 2006.

[12] M. Shen, A. Joseph, J. Wang, F. Z. Peng, and D. J. Adams, "Comparisonof traditional inverters and Z-source inverter," in Proc. Power Electron.Spec. Conf., Jun. 2005, pp. 1692-1698.

[13] O. Lopez, F. D. Freijedo, A. G. Yepes, P. Fernandez-Comesaa, J. Malvar,R. Teodorescu, and J. Doval-Gandoy, "Eliminating ground current in atransformerless photovoltaic application," IEEE Trans. Energy Convers.,vol. 25, no. 1, pp. 140-147, Mar. 2010.

[14] M. C. Cavalcanti, K. C. Oliveira, A. M. Farias, F. A. S. Neves,G. M. S. Azevedo, and F. C. Camboim, "Modulation techniques toeliminate leakage currents in transformerless three-phase photovoltaicsystems," IEEE Trans. Ind. Electron., vol. 57, no. 4, pp. 1360-1368, Apr. 2010. 